psychopharmacology. Amongst the 26 chapters, general reviews, accounts of clinical experiences, more elaborate clinical studies, and reports on experimental work of various degrees of complexity may be found.

The chapters surveying present knowledge cover the treatment of infections of the nervous system with vaccines, sera and antibiotics, anticonvulsants, drugs used in Parkinsonism and other movement disorders, metabolic defects affecting the central nervous system, hormonal factors-particularly adrenal and thyroid-in psychoses, reserpine, phenothiazines, iproniazid, drug addiction, and opiate antagonists. The topics are dealt with in varying detail. The brief and basic approach used in some of these chapters seems unusual for a gathering of specialized workers.

In most cases, reports on individual research accompany the reviewing contributions. Drs. D. M. Woodbury and D. W. Esplin describe work on the metabolism and pharmacodynamics of anti-convulsant drugs. Dr. K. R. Unna and his colleagues present further evidence in favour of the selective inhibition of spinal interneurones by mephenesin and SKF 1045. Two very instructive chapters by Drs. J. V. Brady and H. E. Lehmann discuss methodological points in the evaluation of drug effects on human and animal behaviour, respectively. They are followed by Dr. S. Wolf's cautionary essay on placebos. The story of 2-dimethylaminoethanol, a presumed precursor of acetylcholine and a central stimulant, is traced from animal experiments to clinical trials in schizophrenics by Drs. H. B. Murphree, E. H. Jenney and C. C. Pfeiffer. EEG studies of the action of phenothiazines are described by Drs. E. K. and K. F. Killam, and of nervous stimulants (here differentiated into energizers and anti-depressants) by Dr. H. E. Himwich. The two articles require careful reading but they repay the effort by giving an insight into the possibilities of EEG techniques even to readers not familiar with the method. A very thoroughly documented and illustrated account of the structural effects of tranquillizers is given by Drs. L. Roizin, C. True and M. Knight. Dr. L. Lasagna has taken up the problem of ' misinformation amongst physicians' perpetuated by textbooks and teaching with regard to hypnotics and sedatives. His own large scale observations and those collected from other doctors have brought him to conclusions which ' disagree with most textbooks.' Dr. L. G. Abood reports further instances of increased ceruloplasmin levels in nervous disease. He has also isolated an unstable adrenaline metabolite which produces psychotic symptoms in animals. Another plasma fraction is blamed for psychotic effects by Dr. R. G. Heath and his group. It has been given the euphonious name 'taraxein,' and produced schizophrenic symptoms in volunteering prisoners and monkeys. The discussions which follow these bold hypotheses are less aggressive than one would have feared. An impressive attempt to explain drug effects at the level of neuro-cellular chemistry and microstructure is made by Drs. R. G. Grenell, L. May, W. D. ̊ McElroy and J. Mendelson. The series is con-z cluded by Dr. T. R. Robie's hopeful report on the $\frac{\Phi}{\circ}$ use of iproniazid in melancholia.

The discussions of papers are an integral and $\stackrel{c}{\Rightarrow}$ useful part of books of this type. In this volume chapters are often discussed in groups, which means $-\overrightarrow{-}$ that pertaining remarks have to be located in some cases.

\section{ANESTHESIA FOR INFANTS AND CHILDREN}

By Robert M. Smith, M.D. Pp. 4r8. St. Louis: The C. V. Mosby Co. Distributed in Great Britain by Henry Kimpton, London. 9os.

Dr. Smith's extensive experience of paediatric 3 anaesthesia has enabled him to write a valuable $\dot{\omega}$. work on the subject. Practically every aspect of the management of these small patients is discussed $\stackrel{\oplus}{\oplus}$ in detail, emphasis being rightly placed on the $\omega$ importance of a sound knowledge of infant and child No physiology. Prominence is also given to descrip- $\infty$ tions of disease processes and their implications to음 the anaesthetist; indeed, this is a particularlypleasing aspect of the book that is likely to prove 3 very helpful to the reader seeking knowledge of less commonly performed operations. So far as $\mathcal{S}$ anaesthesia is concerned, Dr. Smith's preference for $\overrightarrow{0}$ inhalational anaesthesia in a closed system and who spontaneous respiration predominates, while the use of muscle relaxants with controlled respirating receives less favour than it would perhaps from a British author. These pages do, however, contain much excellent practical advice on the art of anaesthesia and, after reading them, few will beep able to doubt the importance of special experience $\varrho$ in this interesting branch of anaesthesia. This isö an excellent book, well produced and amply? illustrated and can be thoroughly recommended

\section{FORENSIC MEDICINE, OBSERVATION AND} INTERPRETATION

By A. KeIth Mant, M.D.(Lond.). Pp. 262

London: Lloyd Luke Ltd. I $959.42 \mathrm{~s}$.

There are already three Scottish, four English and a number of American works on legal medicine, $\rightarrow$ and publishers who are business men must have been persuaded that Mant had something in the nature of ' a new work' on the subject beforen accepting it. He has, for this little book makes an entirely practical approach, confining itself to the duties of the doctor, police or coroner's officer and C.I.D. man ' at the scene.' 'Observation and Interpretation' are indeed its key notes, and the author has managed to adhere strictly to the task he set for himself. This is a concise, practical and well illustrated survey from a man of considerable experience of the approach to the body in cases of suspicious or violent death-and in sex offences what to look for and what to say in order to give the? 